\title{
On the experience in development of regional energy policy and strategy
}

\author{
Nikolai Petrov ${ }^{1, *}$, and Natalia Petrova $^{2}$ \\ ${ }^{1}$ Larionov Institute of Physical and Engineering Problems of the North of Siberian Branch of the \\ Russian Academy of Sciences, Yakutsk, Russia \\ ${ }^{2}$ Institute of Finances and Economics, North-Eastern Federal University, Yakutsk, Russia
}

\begin{abstract}
The article presents the main strategies of development features in the concept of energy policy in the Sakha Republic (Yakutia) and the energy strategy of the Sakha Republic (Yakutia) for the period up to 2030.
\end{abstract}

By order of the President and the Government of Russia, the Ministry of Energy and the Ministry of Science of the Russian Federation jointly with the Russian Academy of Sciences have prepared and provided in August 1992 to the Government the Concept of energy policy in the period before the change of the Russian state system and in the initial period of economic transition. At the same time the regions and constituent members of the Federation were recommended to send to the Ministry of Energy of the Russian Federation some energy policy issues that should be fixed in the Concept.

In connection with this, "The Concept of energy policy of the Republic of Sakha (Yakutia)" [1] was developed in 1992, discussed and approved at All-Russian scientific and technical meeting "Energy policy of the Russian Federation and the Sakha Republic (Yakutia) in the new economic conditions", held on August 31 - September 3, 1992 in Yakutsk. The fundamental difference between the concept of energy policy (EP) and previous energy programs consisted in the fact that the emphasis in it was made not on volume indicators of production and consumption of energy resources for which the appropriate funds were to be allocated but for the formation of strategic directions of energy development and mechanisms of implementation of the chosen policy. The digital data contained in EP Concept are not directive indicators, but only forecast estimates that set the social and economic guidelines for making specific decisions.

The most important tasks of the regional energy policy of the Sakha Republic (Yakutia) were:

- allocation of priority areas of structural and technological and technical transformation of all branches of fuel and energy complex in Yakutia;

- transfer of the gravity center to the development of regional energy programs with taking into account specific conditions and new environmental requirements, reliability and safety of energy facilities and systems;

- ensuring legislative, regulatory and economic regulation of energy development to overcome the crisis and effective functioning of all its branches, as well as to determine the ownership of fuel and energy resources and rational distribution of functions between central, regional and local authorities in this area.

The concept of energy policy of the Sakha Republic (Yakutia) consists of seven sections, introduction and conclusion:

\footnotetext{
* Corresponding author: n.a.petrov@iptpn.ysn.ru
} 
- general characteristics of the existing energy sector;

- new conditions for the economy development and expected growth;

- developments directions of branches of fuel and energy complex;

- ways to save energy in the national economy;

- environmental protection;

- changing of the energy balance structure.

Monitoring of the concept implementation was recommended to the Ministry of energy and fuel industry of the Sakha Republic (Yakutia).

After approving by the Russian Government at the end of 1992 the main issues of the "Concept of energy policy of Russia under new economic conditions" and "Energy strategy of Russia for the period up to 2010", the stage of development of periodic energy strategies of the country has been started. The objective preconditions for the development of energy strategy of regions have been arisen. The energy potential of these regions is much higher than the present and future demands of a region (a subject), in development and addition of Energy strategy of Russia. At the same time, one of the most important problems is the necessity to develop the energy strategy for the Northern regions which are in the sphere of strategic interests of the country and should help the Russian economy to overcome this long crisis.

Energy complex and power-fuel supply systems of the North, as an object of study, are significantly different from the similar complexes and systems on the inhabited territories of Russia. For forecasting of energy and energy policy rationale in the North it is necessary to apply such a methodology, the use of which would ensure:

- reliable and uninterrupted power and fuel supply of consumers;

- the leading role of energy in social and economic development of regions and the maintenance of fuel and energy supplies to areas that show a loss of fuel and for export;

- reorientation of priorities in the development of energy complex for the needs of the resident population and the social sphere in order to ensure the conditions of survival and improve the standard of living under conditions of market relations;

- Significant reduction of the environmental impact of energy sector on natural and human environment with increasing environmental restrictions and requirements of safety on power facilities.

However, the development of energy in the North in all its aspects should be subject to common goals and objectives, which is caused by many factors. The marked commonality allowed us to build Hierarchy of tasks of rational directions choice in developing of energy complex of the Republic in the process of its energy strategy development.

We focused on the features of certain aspects included in the hierarchy of tasks in solving the strategy of power development in the Northern region.

Scientific and methodological basis and practice of strategy formation development of the Northern regions (on the example of Yakutia) [2].

Under years of research a strict scheme has been substantiated which forms Energy policy in the region and its implementation starting from the analysis of specific trends in the development of energy in the Northern regions taking into account their natural-climatic and socio-economic features, the substantiation of possible scenarios of their socioeconomic development and completing with mechanism implementations of power strategies providing conditions for such development. The work "Study of technical, economic and environmental features of energy development in the North" fulfilled on the State program of basic researches or the period up to 2000 does not only include information on the program realization volume and directions applied to the region, but also contains practical recommendations for development of scientific research in respect to the Northern regions. As a result of identification and systematization of regional features that influence the development of energy in the North the principles of energy development in 
the North have been formulated in the new social, political and economic situation and the main determining factors have been determined. The adopted in our country methodology of project of energy development prospects under new economic conditions has been adapted and modified taking into account the specifics of the North. The general scientific bases of energy policy for the Northern regions have been developed and scientific grounds and recommendations for the development of energy strategy of the Sakha Republic (Yakutia) have been fulfilled. The information and analytical model of the consolidated fuel and energy balance of the region have been developed as a tool of coordination of projects for the development of industry systems, the consumption rates of electric and thermal energy for household needs on the territory of the Sakha Republic (Yakutia), as well as commercial needs in its agriculture.

Fuel and energy balance in the Sakha Republic (Yakutia), part I [3].

The state and current trends of electric and heat supply of consumers, the main indicators of fuel and energy complex development for 1990-2000 have been analyzed. Changes in the structure of the combined fuel-energy balance and private balances of coal, gas, oil and oil products, electricity and heat have been considered. The analysis and scenarios of the economy development in the Republic for the period 2006-2020 have been given. The retrospective review (1980, 1990-2000) and directions for the development of the fuel and energy complex sectors of the Sakha Republic (Yakutia) for the period 20012006 are meaningfully connected taking into account the trends up to 2020. The development of the energy complex in the Republic for the period up to 2006 was mostly predetermined by proven fuel and energy resources, building capacity in their production, transportation and processing, and most importantly, limited capacity of the economics for funding and logistical support for fuel and energy complex sectors. For the first time on the basis of materials obtained from municipalities (administrative districts), industrial ministries and developed programs, the forecast of dynamics in electricity and heat consumption of the Republic for the period 2001-2006 has been done in territorial section. The characteristic of the Republic sufficiency with reserves of fuel and energy resources and potential of non-traditional renewable energy resources (hydropower resources of small rivers, wind energy, wood wastes) has been given. Based on the analysis of the energy prices forecast in the regions of Eastern Siberia and the Far East, domestic and market capacity countries of North-East Asia and the availability of fuel and energy resources the strategic priorities for the development of the fuel and energy complex of Yakutia have been determined for the period up to 2020 .

Fuel and energy balance of the Sakha Republic (Yakutia), part II, [4].

It has been developed with the support of the Ministry of Economic Development of the Russian Federation and the Federal Agency of Energy (RosEnergo). The paper presents a comprehensive analysis of the fuel and energy balance in the Republic for the period up to 2010 taking into account the trends up to 2020 .

Compared to the first part of the fuel-energy balance of the Sakha Republic (Yakutia) it is significantly extended by methodologically, in terms of forecasting time and coverage of territorial division. In particular, for the first time the cost of fuel and energy balance of the RF subject at the regional level has been estimated. This allowed analyzing material and financial flows in the energy sector of a particular region more extended. The fuel and energy balance has been estimated in four energy regions of the Republic: West Yakutia, Central Yakutia, South Yakutia and North Yakutia. Features and changes in the structure of energy balance, the problems that may occur in the future have been identified. For the first time fuel and energy balances of individual municipalities have been also developed.

"Energy strategy of the Republic of Sakha (Yakutia) for the period up to 2030" (ESRS2030) [5] has been approved by the Government of the Sakha Republic (Yakutia) on October 29, 2009, №441. The supervisors of studies in ESRS-2030 development are the 
corresponding member of RAS A. F. Safronov, doctor of technical Sciences, Professor B. G. Saneev, Ph. D., Professor N.A. Petrov (he is also a principal investigator). Executors: the Institute of Oil and Gas Problems of SB RAS, the L. A. Melentyev Institute of Energy Systems of SB RAS, the V. P. Larionov Institute of Physical and Technical Problems of the North of SB RAS, the VostSibEnergoSetProekt Institute of Irkutsk branch of "Siberian Technical Research centre" JSC, the Financial and Economic Institute of the M.K. Ammosov Yakut State University, and also experts of Executive authorities and the Government of the RS (Ya).

ESRS-2030 has been made on the basis of strategic priorities of socio-economic development in the Sakha Republic (Yakutia), regions of the Far East and Trans-Baikal taking into account the requirements of energy safety and reliability of energy and fuel supply to consumers, conceptual provisions of developed then "Energy strategy of Russia for the period up to 2030" [6] and necessity for solutions of a wide range of tasks of regional, interregional and Federal levels and balance of interests of the center, subjects of the Russian Federation, energy companies, etc., using the basic provisions of the having developed and developed program documents defining the development of economy and fuel-energy complex of the Sakha Republic( Yakutia), the Far East and Trans-Baikal.

The main objective of the development of ESRS-2030: on the basis of long-term scenarios of economic development and taking into account geostrategic interests and security of the country to develop scenarios for the development of fuel and energy complex of the Republic, to determine the possible and economically achievable conditions of mining (production) of energy resources based on the development of existing and new fuel and energy bases and to provide on this basis the conditions for further innovative development of the economy and quality improving of the living standard of the population in the Republic.

ESRS-2030, consisting of a systemically proved set of advanced actions and guideline, is a coordination tool of concerned parties (Federal and regional authorities of executive powers, companies of subsoil users, domestic and foreign economic partners, etc.) to solve important problems of the development of fuel and energy complex of the RS (Yakutia) having the national significance in the long term. The role of the Republic fuel and energy resources in the energy cooperation between Russia and NEA countries in the current XXI century will constantly intensify. The social and economic development of the Sakha Republic (Yakutia) will increasingly depend on the degree of its participation in the formation of inter-regional and global energy markets. Its energy security and efficiency of the economy as a whole depends on rational energy policy in Siberia, the Far East and Russia as a whole, and vice versa, " ... stable and dynamic development of Yakutia is of key importance for both the Far Eastern district and the entire Russia"*

The realization of huge potential of the Sakha Republic (Yakutia) and the availability of practically all natural resources in improvement of energy efficiency on a new technological basis will benefit the Republic under any scenario.

\footnotetext{
* From V. V. Putin's speech at the meeting on socio-economic development of the Sakha Republic (Yakutia). January, 6, 2006 in Yakutsk
} 


\section{References}

1. Concept of energy policy in the Republic of Sakha (Yakutia): Preprint / Petrov N.A. Bredikhin V.I., Burtsev E.M., etc. Yakutsk: Yakut Scientific Center of RAS Publishing house, p. 40 (1997)

2. N.A. Petrov. Scientific and methodical basics and practice in strategy formation of energy development of the Northern regions (on the example of Yakutia). The doctoral dissertation in the form of a scientific report. Irkutsk (1996)

3. Fuel and energy balance of the Republic of Sakha (Yakutia). Part I. Yakutsk: Sakhapoligrafizdat, $160 \mathrm{p}$. (2005)

4. Fuel and energy balance of the Republic of Sakha (Yakutia). Part II. - Yakutsk: Saidam, 280 p. (2006)

5. Energy strategy of the Republic of Sakha (Yakutia) for the period up to 2030. Yakutsk-Irkutsk: "Yakutia" Media Holding, 328 p. (2010)

6. The energy strategy of Russia for the period up to 2030. Approved by the government of the Russian Federation on November 13, 2009. №1715-r. 